\title{
JOÃO CABRAL DE MELO NETO E A TRADIÇÃO POÉTICA PORTUGUESA ${ }^{1}$
}

\author{
JOÃO CABRAL DE MELO NETO AND THE \\ PORTUGUESE POETIC TRADITION
}

Solange Fiuza Cardoso Yokozawa*

\section{RESUMO}

Neste trabalho, proponho acompanhar as complexas relações entre João Cabral de Melo Neto e a literatura portuguesa e o modo como ele se entronca nessa literatura por meio de Cesário Verde, cuja poesia despojada de ornamentos retóricos e que privilegia, entre todos os sentidos, uma visão da realidade concreta, fez com que o autor de Serial nele se reconhecesse e o tomasse como o maior poeta português.

PALAVRAS-CHAVE: João Cabral; Cesário Verde; tradição poética.

\begin{abstract}
In this paper we propose to analyze the complex relationships between João Cabral de Melo Neto and Portuguese literature and the way he fits in this literature through Cesário Verde, whose poetry is stripped of rhetorical ornaments and focuses, among all the senses, a vision of reality. These characteristics made the author of Serial recognize himself in Cesário Verde's poetry and consider him as the greatest Portuguese poet.
\end{abstract}

KEYWORDS: João Cabral; Cesário Verde; poetic tradition. 
A crítica frequentemente enfatiza as relações entre João Cabral de Melo Neto e a Espanha, o que é compreensível, pois é dever do crítico dar a ver as evidências na obra de um autor. Cabral passou dez anos de sua vida diplomática em Barcelona, Madri e Sevilha e estabeleceu uma relação de pertença com a Espanha, mormente com a Andaluzia, região em que reconheceu uma espécie de duplo feminino do seu Pernambuco. A Andaluzia, com sua paisagem, com suas cidades e pessoas que as habitam, com sua cultura, enfim, compõe, com o estado natal do poeta, os dois espaços por excelência de sua poesia. É o próprio Cabral que reconhece essa evidência numa "Autocrítica" bastante citada: "Só duas coisas conseguiram/ (des)feri-lo até a poesia:/ o Pernambuco de onde veio/ e o aonde foi, a Andaluzia" (MELO NETO, 2008, p.430).

Em se tratando especificamente da tradição poética hispânica, que, entre outros veios, fortaleceu-lhe o gosto do concreto sobre o abstrato, Cabral a leu de modo sistemático quando assumiu o posto de vice-cônsul em Barcelona, em 1947, e explicita reiteradamente em entrevistas a influência que ela exerceu sobre sua poesia, por meio, entre outros, do Poema do Cid, de Gonzalo Berceo, de Quevedo e da tradição popular.

Mas se, na fortuna crítica de Cabral, muito se fala em Espanha, as referências que tratam especificamente de suas ligações com Portugal, tendo se ampliado nestes últimos tempos, circunscrevem-se ao exame de confluências entre o poeta e os seus contemporâneos Carlos de Oliveira e Sophia de Mello Breyner Andresen², não havendo leituras mais verticalizadas sobre as relações dele com a tradição poética portuguesa. Isso talvez seja consequência de essas relações terem se efetivado mais tardiamente e serem mais complexas.

Como espaço físico de representação, Portugal é quase uma ausência na poesia cabralina, mesmo tendo o poeta estado várias vezes no país, residido no Porto entre 1985 e 1987, quando encerrou sua carreira diplomática, e mesmo tendo ele, no Porto, segundo Arnaldo Saraiva (2014, p.105), composto ou projetado parcialmente o livro Sevilha andando (1990), escrito quase todo o Crime na Calle Relator (1987) e parte de Agrestes (1985). Numa das duas únicas referências ao Porto, presentes em Sevilha andando, a cidade comparece como espaço disfórico, que contrasta e valoriza o espaço eufórico criado pela projeção imaginária de uma sevilhana numa mulher que passa pela rua. O poema se intitula " $\mathrm{Na}$ cidade do Porto" e assim começa: "Numa dessas tardes vazias,/ em que só se está, não se vive,/ da janela que dá para a rua,/ comercial, consular e triste,// vi passar, entre as que passavam,/ uma mulher de andar sevilha [...]" (MELO NETO, 2008, p.609). A partir daí, desaparece a rua "comercial, consular e triste" e a sevilhana de "esbelto pisar decidido" ocupa todo o espaço.

Se Portugal, como espaço físico, é uma quase ausência na poesia de Cabral, a tradição poética portuguesa é uma presença bastante controversa. 
Primeiro porque, ainda que o poeta chegue a reconhecer, um tanto quanto tardiamente, ser a literatura portuguesa uma das mais importantes do mundo (MELO NETO, 1991, p.9), declara não se identificar muito com ela por considerá-la demasiado subjetiva (MELO NETO, 2014, p.67) e diante dela posiciona-se, pela negativa, como um "antilírico", um "antipoeta", autor de "antiversos".

Além disso, assume um discurso um tanto quanto provocador, desdenhando do coração do cânone da poesia portuguesa: Camões e Fernando Pessoa. Sobre Camões, declara: "Camões era um cidadão que nos obrigava a fazer análise lógica com os textos e aquilo nos dava um enjoo de Camões para o resto da vida" (MELO NETO apud ATHAYDE, 1998, p.31). Poder-se-ia alegar que Cabral ataca não Camões, mas o modo de lê-lo na escola da sua época. Entretanto, se a análise sintática afastou alguns não só do autor de Os lusíadas, mas da poesia de um modo geral, Camões continuou sendo amado por gerações e gerações de leitores, apesar dos métodos de ensino e, em alguns casos, até por causa desses métodos, apesar dos mestres e, em muitas ocorrências, graças aos mestres. Sobre Pessoa, ainda que reconheça ser ele um poeta extraordinário (MELO NETO, 1991, p.9) e se identifique com a centralidade do pensamento na sua poesia (VÉRTICE, 1985, p.142), desdenha do seu "excesso de subjetivismo" tão valorizado pelos brasileiros (MELO NETO, 1991, p.9) e declara preferir Cesário Verde, Camilo Pessanha e até mesmo Miguel Torga a Fernando Pessoa (MELO NETO, 1991, p.9) ${ }^{3}$.

Um outro dado ilustrativo da relação controversa de Cabral com a tradição portuguesa diz respeito ao fato de ele declarar ter lido muito pouco essa literatura, de parecer, em algumas entrevistas, que está a escamotear suas leituras. Na mocidade, diz lembrar-se apenas de Camões, que era obrigado a ler no Colégio e de quem tomou enjoo para o resto da vida, e Eça de Queirós, o escritor preferido de seu pai (MELO NETO apud ATHAYDE, 1998, p.141). A crer no depoimento do poeta concedido a Fábio Freixeiro (1971, p.184) três dias antes de sua posse na Academia Brasileira de Letras, em 1969, esse repertório não teria se ampliado muito na maturidade, pois confessa ser a literatura portuguesa a que menos leu, lembrando-se apenas de Eça de Queirós, António Nobre e Fernando Pessoa, o de Mensagem. É evidente que isso não é verdade, pois, inclusive, na sequência da entrevista, refere-se a uma antologia que Jaime Cortesão lhe confiou organizar para a Editora Livros de Portugal sob o título De Antônio Nobre ao saudosismo, para a composição da qual leu pilhas e pilhas de poetas dessa época, entre os quais Teixeira de Pascoais, que revela ter detestado. Volta Cabral a se referir a essa antologia em 1985, dizendo ter selecionado os poemas, escrito o prefácio, entregado o material, que não foi publicado devido ao fechamento da Editora (MELO NETO apud ATHAYDE, 1998, p.140).

Se Cabral leu mais nomes na tradição portuguesa do que ele declara, há também uma corrente subterrânea dessa tradição presente em sua poesia. Trata-se, primeiramente, da poesia popular, por meio da qual 
o menino de engenho que ele foi descobriu a literatura, como recorda em versos de A escola das facas (MELO NETO, 2008, p.421), e que é a fonte primacial de Morte e vida severina. Essa tradição popular, se genuinamente pernambucana, sem deixar de sê-lo, é também antes portuguesa. Além disso, Cabral foi inicialmente leitor dos modernistas, entre os quais Manuel Bandeira, cuja poesia é fortemente alimentada pela tradição portuguesa popular e livresca. Não obstante isso, é preciso reconhecer que o contato mais efetivo, extensivo e consciente com os clássicos portugueses parece ter se dado tardiamente, depois das influências francesas e hispânicas, provavelmente nos anos 50, quando se estreitam suas relações com intelectuais portugueses. Essas relações repercutiram tanto na sua recepção pela crítica portuguesa (nos anos 60 dá-se um verdadeiro boom de Cabral em Portugal) quanto na presença de poetas portugueses em seus poemas.

Se o conhecimento de Cabral sobre a tradição portuguesa sabe muito mais longe do que suas declarações, até porque, para negar, é preciso conhecer, ele também conhecia poetas mais jovens, entre os quais, além de Miguel Torga, Vitorino Nemésio e Alberto de Serpa. Vitorino Nemésio é autor de um artigo sobre O engenheiro publicado no Diário popular de Lisboa em 15 de junho de 1949, o qual constitui a primeira recepção crítica do poeta em Portugal. Sobre seu primeiro crítico português, Cabral dirá quase 40 anos depois do artigo: "em Portugal, há um grande poeta quase esquecido: Vitorino Nemésio” (MELO NETO apud ATHAYDE, 1998, p. 141). Alberto de Serpa dirigiu com Cabral, em 1949, o volume único da revista $O$ cavalo de todas as cores, confeccionada pelo poeta brasileiro em sua prensa manual sob o selo editorial O Livro Inconsútil e na qual colaboraram Vinícius de Moraes, José Régio, R. Santos Torroella e E. Tormo.

Cabral conhecia também os poetas propriamente de sua geração, entre os quais Alexandre O’Neill e Sophia de Mello Breyner Andresen. Alexandre O'Neill publicou, em Abandono vigiado (1960), uma "Saudação a João Cabral de Melo Neto" que constitui um dos melhores poemas já escritos sobre o poeta brasileiro. Também foi o responsável, juntamente com Alexandre Pinheiro Torres, pela publicação, em Portugal, dos Poemas escolhidos (1963) de Cabral, uma antologia que teve papel fundamental no (re)conhecimento do poeta pela crítica portuguesa. A O’Neill Cabral dedicou um dos seus poemas mais antológicos, o "Catar feijão". Cabral conheceu O’Neill e Pinheiro Torres na casa de Sophia de Mello Breyner Andresen, amiga e, para ele, "o grande poeta" de sua geração em Portugal (MELO NETO apud ATHAYDE, 1998, p.140). À Sophia escreveu o "Elogio da Usina e de Sophia de Mello Breyner Andresen”, saído em A educação pela pedra (1966). Ela, por sua vez, publicou um artigo de difícil acesso e bastante elogioso sobre o poeta (ANDRESEN, 1960) $)^{4}$, dedicou a ele $O$ Cristo cigano, livro de 1961 que foi escrito a partir de uma história que Cabral lhe contou, e ainda publicou em Ilhas, de 1989, um poema crítico muito agudo sob o título "Dedicatória da terceira edição ${ }^{5}$ do Cristo cigano a João Cabral de Melo”. 
Mas, de todos os portugueses, sem dúvida alguma, aquele em que Cabral mais se reconhece é Cesário Verde, tendo dito reiteradamente em entrevistas concedidas em momentos diversos, inclusive no depoimento de 1969 a Freixeiro em que limita suas leituras portuguesas a Eça, Nobre e Pessoa, ser o autor de "O sentimento dum ocidental" o maior de todos os poetas portugueses, o que o fascina (MELO NETO apud ATHAYDE, 1998, p.125), o que teria exercido sobre ele uma "influência reforçativa" (MELO NETO apud FREIXEIRO, 1971, p.190), pois, estando sua espinha dorsal já formada quando o leu, a influência foi no sentido de fortalecer uma tendência já estabelecida. Aos 76 anos ainda reforça: "entre os portugueses, antigos e modernos, cito Cesário Verde. É o maior poeta lusitano, com quem mais me identifico, por causa daquela ausência de retórica, uma visão voltada para o mundo exterior" (MELO NETO, 1996, p.29).

O momento máximo da reverência cabralina a Cesário Verde é o poema seriado "O sim contra o sim", de Serial (1961). Nesse poema-série, Cabral lê poética e criticamente, em dupla, poetas e pintores de sua predileção, nomeadamente os poetas Marianne Moore e Francis Ponge, Cesário Verde e Augusto dos Anjos, além dos pintores Miró e Mondrian, Juan Gris e Jean Dubuffet.

Cesário é lido ao lado de Augusto dos Anjos, de modo que o reconhecimento de Cabral numa tradição portuguesa coincide com o seu reconhecimento numa tradição brasileira. É verdade que nos seus livros iniciais é patente o débito para com poetas mais recentes, mormente $\mathrm{Mu}$ rilo Mendes e Carlos Drummond de Andrade, mas sua reverência a uma tradição nacional um pouco mais recuada é tardia.

Nesse sentido, a tese de Abel Barros Baptista de que Cabral representaria o triunfo do nacionalismo romântico-modernista precisa ser considerada, mas com restrições. A leitura que Barros Baptista realiza de Cabral ocupa um lugar fundamental em sua proposta de desvincular, em $O$ livro agreste, a literatura brasileira do projeto de nacionalidade sustentado por Antonio Candido e seus continuadores. Como a literatura brasileira, conforme esse projeto, teria se constituído, primeiro, negando Portugal (Romantismo), depois, desinteressando-se dele (Modernismo), Cabral, que reconhece o débito dos poetas de 45 para com os de 30, vendo naqueles uma extensão das conquistas destes, seria "o primeiro grande poeta brasileiro a formar-se no quadro delimitado da poesia brasileira e o primeiro em cuja poesia, particularmente, não existe qualquer diálogo com a tradição poética portuguesa" (BAPTISTA, 2005, p.50). Representando o triunfo do Modernismo, Cabral também seria o primeiro importante exemplo da impossibilidade desse triunfo, pois, para continuar sendo vanguarda, precisa romper com o cânone, ou seja, ou a tradição de 22 continua modernista ou continua brasileira. Também segundo Baptista, Cabral se abeira de Drummond, poeta que, com seu Claro enigma, livro que reenvia a uma tradição portuguesa, representa a pedra básica da destruição do cânone modernista. 
Não cabe aqui discutir as (des)razões da densa narrativa crítica de Barros Baptista sobre a perspectiva nacionalista de certa crítica brasileira e da obra daquele que é o maior crítico do Brasil - o que não quer dizer que não tenha cometido equívocos -, mas apenas ponderar a respeito do lugar de Cabral nessa narrativa.

Primeiramente, vale esclarecer que Cabral não se formou "no quadro delimitado da poesia brasileira". Ainda que o poeta reconheça o seu débito para com os modernistas de 30 , ele, por meio da biblioteca de Willy Lewin, o mentor do grupo de intelectuais que frequentava no Café Lafayete no Recife, teve acesso a obras de surrealistas e cubistas, duas influências centrais em seu livro de estreia que não passaram despercebidas a Antonio Candido (2002, p.140) em resenha sobre o livro na qual reconhece uma grande promessa no jovem poeta estreante - que não faz feio, mas está longe de ser o poeta central e de exceção em que se tornou. Às leituras surrealistas e cubistas iniciais, somam-se aquelas de Mallarmé e Valéry, com os quais o poeta compartilha muitas confluências teórico-críticas.

Também a alegação do crítico da não existência, em Cabral, de "qualquer diálogo com a tradição poética portuguesa", se não improcedente quando se consideram suas declarações, precisa ser repensada quando se examina sua obra. Primeiro, como já mencionado, há uma leitura indireta da tradição portuguesa por meio da leitura de outros poetas leitores dessa tradição. Como há, a partir dos anos 50, a presença da literatura oral portuguesa via folclore pernambucano. Também se não há, até 1961, na obra de Cabral, "qualquer diálogo [explícito] com a tradição poética portuguesa" ou, poder-se-ia acrescentar, se o poeta diz em entrevistas não se identificar com essa tradição, como também declara não se identificar com a tradição brasileira, isso, mais do que consequência de um alheamento ou de uma negação pontual em nome de um projeto nacionalista, é decorrência de uma postura fortemente negativa frente a uma questão central para a poesia lírica que é a determinação do eu. Sendo a poesia luso-brasileira marcadamente subjetiva, não poderia ele, pois, nela se reconhecer facilmente. São palavras do poeta:

Um crítico brasileiro disse que eu sou o poeta mais estranho e distante da tradição do lirismo português e brasileiro

[...]

O que limita as duas poesias, [...] a portuguesa e a brasileira, é serem excessivamente líricas e, como tais, exclusivamente subjetivas. E, como subjetivas, correm o perigo de cair no sentimentalismo. (MELO NETO, 1961, 68-69)

Inclusive com a tradição brasileira que lhe é mais próxima, a modernista, Cabral estabelece uma vinculação complexa, de que é exemplar a sua relação com Bandeira. Primos, os poetas se corresponderam, tendo Cabral editado o Mafuá do malungo pela Editora O Livro Inconsútil. Influência inicial, o poeta dedicará a Bandeira um livro da maturidade que representa o momento máximo do seu antilirismo, A educação pela pedra 
(1966), com as seguintes palavras: "A Manuel Bandeira esta antilira para seus oitent'anos" (MELO NETO, 2008, p.308). A dedicatória, que simboliza uma reverência a um dos poetas mais autenticamente líricos da poesia brasileira moderna, de veio reconhecidamente casimiriano, também soa irônica, não deixando o dedicador de marcar o seu lugar nos antípodas daquele a quem o livro é dedicado. Mais tarde, em Agreste, Cabral publica um "Último poema", paródia do poema homônimo de Bandeira saído em Estrela da manhã, e do estilo do autor, ao mesmo tempo em que constitui uma afirmação da sua "antilira", do seu "antiverso". Com Drummond não é diferente. Influência inequívoca nas primeiras obras do poeta, presente desde a dedicatória de Pedra do sono e $O$ engenheiro e da epígrafe fundadora de Os três mal amados, Drummond é sempre lembrado por ele como o maior poeta brasileiro. Mas o Drummond requestado por Cabral não é, como o quer Barros Baptista, o dos poemas classicizantes, e sim o modernista, conforme o ratificam o exame da obra e as palavras do próprio poeta: "O que mais apreciei nele [Drummond] foi a dicção áspera, cortada e prosaica, que contrastava com a dicção fluente que muitos associam à poesia; foi a antipoesia discursiva; foi, nos primeiros livros, a construção do poema mais para a vista do que para o ouvido" [...] "Dou pouca importância à segunda parte da sua obra, que é retórica” (MELO NETO, 1988, p.VII).

Portanto, a relação de Cabral com a tradição poética portuguesa não pode ser pensada como triunfo do nacionalismo modernista por meio de uma ausência de diálogo com Portugal, mas como negação de uma tradição lírica fundada na subjetividade. Negar essa tradição, negar a sua tradição, que é, antes de todas, a luso-brasileira, não é ser indiferente a ela, mas situar-se originalmente diante dela para poder continuá-la, revigorando-a.

Não casualmente, quando o poeta já maduro de Serial homenageia a tradição brasileira e portuguesa, nela se entroncando, escolhe, para fazê-lo, dois poetas de exceção: Augusto dos Anjos e Cesário Verde. Entre os dois, a considerar não só o poema a ele dedicado, mas também os depoimentos de Cabral, o português é tomado como o pai poético por excelência, como aquele que está a contrapelo do excessivo lirismo luso-brasileiro, visto pelo antilírico como um defeito: "Cesário Verde não é lírico; é subjetivo [...] descreve a realidade através da qual se sente a alma do poeta, mas não por transcrição abstrata” (MELO NETO, 1961, p.69).

Vamos, finalmente, ao poema dedicado a Cesário na série "O sim contra o sim":

\section{A Felix de Athayde}

Cesário Verde usava a tinta

de forma singular:

não para colorir,

apesar da cor que nele há.

Talvez que nem usasse tinta, somente água clara, 
aquela água de vidro

que se vê percorrer a Arcádia.

Certo, não escrevia com ela,

ou escrevia lavando:

relavava, enxaguava

seu mundo em sábado de banho.

Assim chegou aos tons opostos

das maçãs que contou:

rubras dentro da cesta

de quem no rosto as tem sem cor. (MELO NETO, 2008, p. 275)

Esse poema e os demais da série seguem uma estratégia empregada de modo recorrente por Cabral para ler poética e criticamente outros poetas e criadores de um modo geral, isto é, evidenciando-lhes o modus operandi, o qual termina revelando aspectos da própria poíesis cabralina.

Na primeira quadra, a voz poética propõe uma metáfora: "Cesário Verde usava a tinta/ de forma singular" e vai, ao longo do poema, explicá-la, negá-la e substituí-la por outra, num procedimento metafórico reconhecivelmente cabralino. Por meio dessa metáfora inicial, Cesário é aproximado da arte pictórica, o que não constitui novidade na sua recepção crítica, em que é tido por David Mourão-Ferreira ([1981], p.69) como "um pintor nascido poeta" e em que há várias alusões e estudos verticalizados sobre sua relação com a arte pictórica, notadamente o impressionismo. Com isso, Cabral aproxima Cesário de si, na medida em que a sua poesia é extremamente plástica, sendo também amiúde lida em clave comparativa com a pintura.

Na sequência da quadra, explica-se a metáfora da tinta usada "de forma singular" por Cesário Verde: "não para colorir,/ apesar da cor que nele há." A explicação não só estabelece um paradoxo (uma tinta que não colore), mas o faz por meio de outra metáfora, já que o "colorir" aqui assume o sentido figurado de disfarçar, encobrir o lado menos agradável da realidade.

A segunda quadra retifica, num discurso modulado e por meio de outra metáfora, a metáfora inicial ("Talvez nem usasse tinta,/ somente água clara"), associando, inclusive, a água usada pelo poeta com a "água de vidro" da Arcádia.

A imagem "água de vidro" evocando os rios da paisagem árcade não só reforça visualmente a limpidez do líquido usado por Cesário, mas também convoca metonimicamente o Arcadismo. Na tradição brasileira, uns dos poucos poetas declaradamente apreciados por Cabral, também tardiamente, pois declara tê-los lido na Antologia organizada nos anos 1950 por Sérgio Buarque de Holanda, são os da fase colonial (MELO NETO apud FREIXEIRO, 1971, p.184). Isso por tal poesia se pautar em valores caros a Cabral, como a centralidade da razão, o equilíbrio, as convenções. Cabral era um saudoso das épocas clássicas, quando regras coletivas mediavam 
o trabalho criativo e serviam para aferir o valor de uma obra. Também mostra-se um criador profundamente incomodado com a liberdade e a pluralidade de poéticas da modernidade e termina por traçar um conjunto de restrições criativas em seus livros, de que são pontos máximos Serial e A educação pela pedra. Paradoxalmente, não teria construído sua obra originalíssima e de exceção não fosse a modernidade uma época em que cada artista tem de forjar sua própria poética. Assim, ao associar o instrumento de trabalho de Cesário Verde ("água de vidro") com o Arcadismo e, por extensão, com o Classicismo, Cabral termina por vincular o seu precursor a uma tradição que lhe é cara.

Na terceira estrofe, a voz poética crítica procede a uma nova explicação retificadora, desta vez em tom peremptório, esclarecendo que, como poeta, como artista que recorre à linguagem dos homens, Cesário não poderia escrever com água (“Certo, não escrevia com ela”). É como se explicasse ao leitor que escrever com água é uma metáfora. Mas, na sequência, propõe outra metáfora: "escrevia lavando". O verbo "lavar", reiterado na estrofe ("lavava", "relavava”), estabelece uma relação antitética com o "colorir" da primeira estrofe, de modo que Cesário é aquele que, em lugar de colorir, encobrir o lado menos agradável da realidade, lavava-a, deixando esse lado mais perceptível. Esse verbo estabelece também uma conexão entre o poeta lido e o seu leitor, pois remete à poesia das "coisas claras", ao "mundo que nenhum véu encobre" (MELO NETO, 2008, p.45) que Cabral já pressente como ideal de poesia desde o seu O engenheiro (1945).

A quarta e última quadra, de caráter prosaicamente conclusivo, remete ao produto a que chegou Cesário ao se valer do procedimento descrito nas estrofes anteriores. A estrofe intertextualiza o poema "Num bairro moderno", de modo que o tipo de composição verdiana cujo processo foi descrito no poema é aquele composto por peças estruturadas a partir do mesmo processo desse poema.

Em "Num bairro moderno" (VERDE, 2006, p.110-113), o sujeito lírico segue para o trabalho por uma rua larga modernamente pavimentada de macadame. Entretanto, em lugar de olhar sem ver o mundo à sua volta, como é típico de quem vai para o trabalho, ele tem a vista ferida pela vida que pulsa no bairro por onde passa, centralmente por uma rapariga que, dentro de uma cesta, traz um "retalho de horta", um pedaço do campo para alimentar a cidade. Humilhada por um criado, que se recusa a pagar mais pelo produto e lhe "[a] tira um cobre ignóbil, oxidado,/ Que vem bater nas faces d'uns alperces" (p.111), a vendedora recebe a solidariedade do sujeito lírico, cuja reação ética se faz, antes e sobretudo, por meio de uma solução estética, isto é, transfigurando artisticamente os vegetais da "giga" da vendedora "engelhada, feia" e de "bracinhos brancos", transformando-os, à maneira do pintor Arcimboldo, em ser humano. Também, atendendo a um pedido da rapariga, ajuda-a a levantar a cesta, não sem uma autoironia, extensiva a todos os de sua classe quando fazem concessões virtuosas aos pobres: "Eu acerquei-me dela, sem desprezo [...] E recebi, naquela despedi- 
da,/ As forças, a alegria, a plenitude,/ Que brotam d'um excesso de virtude/ Ou d'uma digestão desconhecida" (p.112).

A parte do poema verdiano aludida por Cabral remonta à estrofe em que o sujeito lírico segue "para o lado oposto" ao da vendedora, sinalizando não apenas o seu deslocamento físico, mas também a irreparável fratura entre ele e a personagem social com quem se solidariza: "E enquanto sigo para o lado oposto,/ E ao longe rodam umas carruagens,/ A pobre afasta-se, ao calor de agosto,/ Descolorida nas maçãs do rosto,/ E sem quadris na saia de ramagens" (p.112). O poema de Cabral retoma essa estrofe, evidenciando o contraste estabelecido entre as faces descoloridas da pobre vendedora e o intenso colorido do conteúdo da cesta.

Interessante é que a voz poética refere-se ao verbo "contar" em lugar de "cantar" para dizer a representação poética que Cesário faz da face da rapariga e do conteúdo da cesta ("Assim chegou aos tons opostos/ das maçãs que contou:"). "Contar" pode, no poema, significar tanto "narrar", "relatar" quanto "verificar a quantidade", "computar". No primeiro sentido, o termo escolhido é bastante acertado para dizer o modo poético de Cesário, que, no poema em questão e em outros, assume uma atitude narrativa. Também é bastante apropriado para dizer o modo criativo de Cabral, que cultivou o poema que conta, o poema narrativo, gênero que já praticava com sucesso quando da publicação de Serial. No segundo sentido, o "contar", computar, poderia ser índice linguístico da intenção de Cabral de atribuir a Cesário um desejo, que é seu, de criar como um matemático, sempre a partir de elementos racionais, banindo tanto quanto possível a inspiração (MELO NETO, 1999, p.328).

Cabral poderia ter escolhido o verbo "cantar" em lugar de "contar". Até porque o "cantar" satisfaz melhor à expectativa do leitor, pois trata-se de um verbo mais frequente para nomear o gesto poético, mesmo em se tratando de uma poesia assinalada por um fio narrativo, como a de Cesário. Preferir "contar" a "cantar", verbo que está associado à história do gênero lírico, é também, portanto, uma forma de negar a tradição lírica a que o termo está associado. Mais do que isso, é um modo de atribuir ao pai poético o mesmo antilirismo, o mesmo gesto negativo que assinala o filho diante da tradição.

Do poema "Num bairro moderno" e do processo poético de Cesário Verde, João Cabral apreende e descreve, valorizando, a tendência verdiana de fazer uma poesia voltada para a realidade exterior, de modo que, ao descrever a engrenagem poética do outro, destaca nela aquilo que é comum à sua própria poesia.

Essa poesia voltada para o mundo concreto, tanto no caso de Cesário quanto no de Cabral, fez com que os dois propusessem, cada um no seu tempo e ao seu modo, um novo conceito de poesia lírica. Isso porque um poeta escreve tendo em mira, simultaneamente, o contexto em que lhe é dado viver e a tradição poética em relação à qual se situa. 
Essa tradição encontra sua principal formulação teórica em Hegel (1997), que entende a poesia lírica como expressão da subjetividade do homem que escreve, de modo que, mesmo quando o poeta se volta para o mundo exterior, este é apenas o ponto de partida para a expressão da sua intimidade.

Cesário reconfigura o lirismo português ao dar expressão poética à realidade quotidiana numa linguagem corrente e comum, sendo o primeiro a cortar, verdadeiramente, com a retórica romântica, com o sentimentalismo difuso, como se pode verificar em poemas como "Num bairro moderno", "O sentimento dum ocidental" e "Cristalizações". Entretanto, antes desses poemas, naqueles compreendidos entre 1873 e 1876, já se nota uma ruptura com o conceito romântico de poesia lírica ainda vigente entre os contemporâneos do poeta, os quais, exatamente por isso, não souberam ver a ironia, marca do sujeito lírico verdiano, e criticaram, como se deu com As farpas de Ramalho Ortigão, os versos daquele que esperava acolhida entre os seus. Nesse sentido, Jorge de Sena (2001, p.179) diz que a ironia "constitui uma das chaves da essencialidade lírica de Cesário Verde", que não poderia ser compreendido pela "gente das Conferências do Casino", para os quais "a 'autêntica' poesia continuava a ser [...] o refúgio idealista, a compensação purificada daquele mesmo idealismo banal de Regeneração que eles impiedosamente desmascaravam em suas obras, e que mais tarde aceitaram".

Tendo Cesário incorporado à poesia um recurso como a ironia, que é, segundo Mario Higa (2010, p.46), próprio da prosa de ficção, mas não da poesia dos revolucionários de Coimbra, estes, "munidos de critérios romântico-sentimentais que definiam a poesia lírica como expressão sincera de sentimentos nobres e humanitários", rechaçaram a poesia verdiana. Destarte, um poema como "Esplêndida" foi duramente criticado por Ramalho Ortigão, que não teria lido ou não teria podido ler que os excessos, o mau gosto e as inadequações com que é descrita a fidalga soberba constituem antes uma ironia a essa personagem do que uma homenagem respeitosa. Também o crítico ofendeu-se profundamente com o rebaixamento do eu lírico do poema, não considerando, segundo Higa (2010, p.43), "que a coerência narrativa do poema exigia um sujeito lírico psicologicamente perturbado para que se construísse o elogio irônico da mulher esplêndida", já que um narrador equilibrado e consciente construiria antes um discurso moralista, impossibilitando a ironia do texto.

O fingimento poético que está na base desses poemas verdianos leva Jorge de Sena (2001, p.179) a notar que, apesar dos elementos autobiográficos que o compõem, o lirismo de Cesário não é confessional, como se pode comprovar pela insistência do motivo do "pobre" desprezado pela "grande dama" em poemas cujo autor empírico é um abastado comerciante de Lisboa, com quintas em Linda-a-Pastora.

Em "Cadências tristes" (VERDE, 2006, p.93), o poeta recorre, como estratégia de fingimento, a uma voz lírica feminina para fazer a ho- 
menagem a João de Deus; homenagem "bastante má", no dizer de Jorge de Sena (2001, p.179). Como informa Joel Serrão (In: VERDE, 2003, p.91), o poema foi publicado pela primeira vez em A Tribuna, de Lisboa, em dezembro de 1874, sob o pseudônimo Margarida. Com isso, o poeta furta-se de fazer, ele mesmo, o elogio do popular e venerado poeta do amor; elogio que soa sincero na voz feminina, mas que, ironicamente, limita-lhe o "cândido lirismo", ameaçado pelos que querem "proscrever a sensibilidade", a um alcance feminino ("Poeta da mulher!”).

Em relação a esse poema, David Mourão-Ferreira ([1981], p.68) destaca que o verso "O sentimentalismo há-de mudar de fases" "é um aviso: ressalvando embora a perenidade daquela fase do nosso sentimentalismo que termina com o próprio João de Deus, Cesário Verde prepara-nos para nova fase, que virá, aliás, a ser em grande parte inaugurada por ele" (ênfases do autor).

Cabral, por sua vez, quando define seu modo poético, o que se dá de modo mais pleno no livro Psicologia da composição, entende que o poeta deve fugir da sua personalidade em poesia. Mais significativo nesse sentido é o grupo de poemas que dá nome ao livro, em que, logo no poema de abertura (MELO NETO, 2008, p.93), a voz lírica declara em tom peremptório: "Saio do meu poema/ como quem lava as mãos". A expressão-clichê "lavar as mãos" pode dizer respeito tanto ao fato de o poeta se desligar da obra criada quanto a uma assepsia da personalidade do criador no processo de composição. A experiência pessoal não é simplesmente negada, que a voz lírica reconhece a sua presença, mas depurada, impessoalizada, tornando-se realidade dissipada e ausente, como "a camisa/ vazia que despi".

A partir de O cão sem plumas (1950), a fuga da poesia expressiva encontra sua realização por meio da representação de uma dada realidade exterior, que será, ao longo da obra de Cabral, predominantemente, Pernambuco e Andaluzia.

O ponto culminante da extirpação do eu na poesia cabralina é A educação pela pedra, livro em que o poeta elimina a primeira pessoa discursiva. É evidente que a figuração da intimidade em um poema não pode ser aferida levando-se em conta apenas a pessoa discursiva, mas o banimento do pronome "eu", em Cabral, implica a negação de uma tradição de poesia expressiva e a afirmação de uma poesia objetiva, voltada para a realidade concreta.

Mas o próprio Cabral, sempre o primeiro crítico de si, como todo grande poeta, nesse livro em que leva ao paroxismo a prática de uma poesia objetiva, problematiza essa objetividade, reconhecendo, em "Retrato de escritor" (MELO NETO, 2008, p.336), que o processo da escrita é também uma autoescrita, uma escrita de si. É assim que o escritor "se passa a limpo" ao "escrever da dor indonésia/ lida no Rio, num telegrama do Egito", se faz solúvel na tinta de escrever, "manando seu autoescrito". 
Um poeta que evita se expressar, que, quando se expressa, procura fazê-lo de modo dissimulado, numa aparente impassibilidade, tem dificuldade de se reconhecer numa tradição de forte subjetividade como a portuguesa. Precisa negá-la para melhor continuá-la e antes de nela se reconhecer, o que se dá, central e simbolicamente, por meio da eleição de Cesário Verde como pai poético.

\section{REFERÊNCIAS BIBLIOGRÁFICAS}

ANDRESEN, Sophia de Mello Breyner. A poesia de João Cabral de Melo Neto. Encontro, [s.1.], n.28, p.12, abr. 1960.

ATHAYDE, Félix (org.). Ideias fixas de João Cabral de Melo Neto. Rio de Janeiro: Nova Fronteira/FBN; Mogi das Cruzes, São Paulo: Universidade de Mogi das Cruzes, 1998.

BAPTISTA, Barros. O livro agreste: ensaio de curso de literatura brasileira. Campinas, São Paulo: Editora da UNICAMP, 2005.

CANDIDO, Antonio. Notas de crítica literária - poesia ao norte. In:_. Textos de intervenção. Seleção, apresentação e notas de Vinícius Dantas. São Paulo: Duas Cidades; Ed. 34, 2002. p.135-142.

FREIXEIRO, Fábio. João Cabral de Melo Neto - roteiro de auto-interpretação. In:__. Da razão à emoção II; ensaios rosianos e outros ensaios e documentos. Rio de Janeiro: Tempo Brasileiro, 1971. p.179-192.

HEGEL, G.W.F. Curso de estética: o sistema das artes. Trad. Álvaro Ribeiro. São Paulo: Martins Fontes, 1997.

HIGA, Mario. Introdução. VERDE, Cesário. Poemas reunidos. Introdução e notas Mario Higa. Cotia, São Paulo: Ateliê, 2010. p.15-87.

MELO NETO, João Cabral. Entrevista ao Jornal de letras, artes e ideias (Portugal, Espanha, Brasil... a poesia). In: SARAIVA, Arnaldo. Dar a ver e a se ver no extremo: o poeta e a poesia de João Cabral de Melo Neto. Porto: CITCEM, Edições Afrontamento, 2014. p.65-72.

. Poesia completa e prosa. Rio de Janeiro: Nova Aguilar, 2008.

. Entrevista de João Cabral de Melo Neto. In: SECCHIN, Antonio Carlos. João Cabral: a poesia do menos e outros ensaios cabralinos. 2.ed. rev. amp. Rio de Janeiro: Topbooks, 1999.

Entrevista. In: CADERNOS DE LITERATURA BRASILEIRA. João Cabral de Melo Neto. São Paulo: Instituto Moreira Sales, 1996. p.18-31.

. João Cabral de Melo Neto [entrevista a Maria Leonor Nunes]. Jornal de letras, artes e ideias, p.8-9, 5 fev. 1991.

João Cabral de Melo Neto: depoimento em forma de entrevista (concedida a Arnaldo Saraiva). Jornal do fundão, ano 43, n.2162, p.VII, jan. 1988. 
meu tempo: entrevistas. Lisboa: [s.n.], 1961. p.63-73.

MOURÃO-FERREIRA, David. Notas sobre Cesário Verde. In: Hospital das Letras. 2.ed. Lisboa: Imprensa Nacional e Casa da Moeda [1981].

SARAIVA, Arnaldo. Dar a ver e a se ver no extremo: o poeta e a poesia de João Cabral de Melo Neto. Porto: CITCEM, Edições Afrontamento, 2014.

SENA, Jorge. A linguagem de Cesário Verde. In: Estudos de Literatura Portuguesa I. Lisboa: Edições 70, 2001. p.177-181.

VERDE, Cesário. Cânticos do realismo e outros poemas. 32 cartas. Direção de Teresa Sobral Cunha. Lisboa: Relógio D’Água, 2006.

VERDE, Cesário. Obra completa de Cesário Verde. Pref., org. e notas de Joel Serrão. 8.ed. Lisboa: Livros Horizontes, 2003.

Recebido para publicação em 14/06/2015

Aprovado em 22/08/2015

\section{NOTAS}

* Professora associada da Universidade Federal de Goiás (2002), onde atua em nível de graduação e pós-graduação. Doutorou-se em Letras - Literatura Brasileira, na Universidade Federal do Rio Grande do Sul (2000). Desenvolveu, na Faculdade de Letras da Universidade do Porto, Portugal, sob supervisão do professor Dr. Arnaldo Saraiva e financiamento do $\mathrm{CNPq}$, investigação de pós-doutoramento sob o título Reconfigurações da Poesia Lírica em Cesário Verde e João Cabral. Coordena o projeto Poesia Brasileira Contemporânea e Tradição, financiado pela FAPEG. É líder, no Diretório do CNPq, do Grupo Estudos de Poesia Brasileira Moderna e Contemporânea.Entre várias outras publicações, é autora do livro A Memória Lírica de Mario Quintana (2006) e coorganizadora dos livros O Legado Moderno e A (Dis)solução Contemporânea (2011) e Poesia Brasileira Contemporânea e Tradição (2015).

1 Artigo vinculado ao projeto de pós-doutoramento "Reconfigurações da poesia lírica em Cesário Verde e João Cabral”, desenvolvido na Faculdade de Letras da Universidade do Porto (março a agosto/2015), com financiamento do CNPq, e no Instituto de Letras da Universidade Federal Fluminense (setembro/2015 a março/2016).

2 Sobre Cabral e Breyner Andresen, cito os seguintes trabalhos, todos publicados na última década: 1) MARTELO, Rosa Maria. Prefácio. In: ANDRESEN, Sophia de Mello Breyner. O Cristo cigano. Lisboa: Assírio \&Alvim, 2014; 2) EIRAS, Pedro. Faca partilhada. In: __. A lenta volúpia de cair. Vila Nova de Famalicão: Quasi, 2007; 3) VERUNSCHK, Micheliny. Confluências entre João Cabral de Melo Neto e Sophia de Mello Breyner Andresen: poesia das coisas e espaços. Dissertação (Mestrado), Programa de Pós-Graduação em Literatura e Crítica Literária, Pontifícia Universidade Católica de São Paulo, 2006. Sobre as confluências entre Cabral e Carlos de Oliveira, registro, além do artigo pioneiro de Ida Alves (ALVES, Ida. Cultivar o deserto - encontro entre Carlos de Oliveira e João Cabral de Melo Neto. Convergência lusíada, Rio de Janeiro, v.2, n.18, 2001), duas teses: 1) COELHO, Cláudia. Memória e metapoesia em João Cabral de Melo Neto e Carlos de Oliveira. Tese (Doutorado), Programa de Pós-Graduação em Estudos Comparados de Literaturas 
de Língua Portuguesa, Universidade de São Paulo, 2011; 2) GANDOLFI, Leonardo. Entre Carlos de Oliveira e João Cabral de Melo Neto: errar a paisagem. Tese (Doutorado), Programa de Pós-Graduação em Letras, Universidade Federal Fluminense, 2012.

3 No trabalho "Fernando Pessoa e João Cabral: leitores de Cesário Verde”, apresentado, em 2015, no Congresso 100Orpheu de Lisboa, e a sair nas atas do evento, apresento algumas possíveis razões para entender por que Cabral, mesmo tomando, a exemplo de Pessoa, Cesário como precursor e nele valorizando a mesma poesia objetiva cara a Pessoa, faz restrições ao modernista português.

4 Agradeço a Rosa Maria Martelo, que me apresentou o artigo de Sophia e dele me ofereceu, generosamente, uma cópia.

5 Nas edições dos livros da autora pela Caminho, aparece "segunda edição". 